\title{
Lectin detection of renal glycogen in rats with short-term streptozotocin-diabetes
}

\author{
R.A.Hennigar, R. K. Mayfield, J. N. Harvey, Z.-H.Ge and D. A. Sens \\ Departments of Pathology and Medicine, Veteran's Administration Hospital and Medical University of South Carolina, Charleston, \\ South Carolina, USA
}

\begin{abstract}
Summary. Earlier histochemical findings from our laboratory have shown that a lectin (agglutinin) from Griffonia simplicifolia, which reportedly binds to terminal $\mathrm{N}$-acetylglucosamine residues in glycoconjugate oligosaccharides also shows affinity for glycogen. In the present study, the lectin was conjugated to horseradish peroxidase and applied to paraffin sections of kidney from streptozotocin-diabetic rats, insulintreated and untreated, and age-matched control rats. Griffonia simplicifolia agglutinin II detected glycogen in cortical ascending thick limbs of untreated diabetic rat kidneys as early as $24 \mathrm{~h}$ following injection of streptozotocin. The number of stained cells increased steadily so that by day 14 of diabetes the lectin reacted with nearly all of the cells lining ascending thick limbs in the cortex and adjacent outer stripe of the outer medulla. Glycogen was never identified in the inner medullary stripe. Comparison of Griffonia simplicifolia agglutinin II and periodic acid-Schiff staining revealed that periodic
\end{abstract}

acid-Schiff could not clearly detect glycogen until 14 days following injection of streptozotocin, which substantiated earlier claims that Griffonia simplicifolia agglutinin II might be a more sensitive indicator of glycogen than periodic acidSchiff. The distribution of glycoconjugate containing terminal $\mathrm{N}$-acetylglucosamine stainable with the lectin was unchanged in diabetic kidneys. Griffonia simplicifolia agglutinin II served in the present study to further characterise the sequence of abnormal glycogen accumulation in streptozotocin-diabetic rat kidneys. In addition, it was shown that the lectin's ability to antedate periodic acid-Schiff detection of glycogen has utility in histochemical investigations in diabetes.

Key words: Experimental diabetes, lectins, kidney, glycogen, streptozotocin.
Recently we reported that an $\mathrm{N}$-acetylglucosaminebinding lectin isolated from Griffonia simplicifolia, termed Griffonia simplicifolia agglutinin II (GSA II), stained glycogen in paraffin sections from various rodent and human tissues [1]. This latter study also suggested that GSA II might be a more sensitive indicator of glycogen than the more traditionally used periodic acid-Schiff (PAS) reaction. Conceivably this attractive property of GSA II could be exploited to study histochemical changes in tissues from diabetic human or animal models, since disordered carbohydrate metabolism in diabetes mellitus may result in altered glycogen synthesis and degradation.

Accordingly, we employed GSA II conjugated to horseradish peroxidase to characterise lectin binding sites in kidneys from streptozotocin-diabetic rats and compared them with lectin-reactive foci in agematched control rat kidneys. The effects of insulin treatment upon any staining alterations produced by streptozotocin-induced diabetes were also examined.
This particular model was chosen for study because glycogen accumulates abnormally in the distal nephron of streptozotocin-diabetic rats [2]. The present study showed that GSA II-HRP detected glycogen deposition much earlier than PAS and illustrated the lectin's usefulness in examining the effects of diabetes mellitus upon kidney.

\section{Materials and methods}

Twenty-four male Sprague-Dawley rats $(180-215 \mathrm{~g})$ were used in the first phase of the study. Seventeen animals were injected intravenously with streptozotocin $(65 \mathrm{mg} / \mathrm{kg}$ body weight). Seven uninjected rats served as controls. Tail vein plasma glucose concentration was measured by the glucose oxidase method [3] 1-2 days after streptozotocin injection to confirm diabetes. On the next day, eight of the diabetic rats were randomly selected and begun on insulin treatment. Subcutaneous injections of $1.75 \mathrm{U}$ protamine zinc insulin (Protamine Zinc and Iletin, Eli Lilly and Company, Ind, USA) were given between 09.00 and 10.00 hours daily. All animals were housed 3-4 per cage and allowed free access to food and water. 
After 13 days, tail vein plasma glucose was measured in all rats at 09.00 and 21.00 hours and the values averaged for each animal. The following day, all rats were anaesthetised with inactin $(100 \mathrm{mg} / \mathrm{kg})$ and kidneys were excised, sliced thinly and fixed for $12-18 \mathrm{~h}$ at $4{ }^{\circ} \mathrm{C}$ in a $6 \% \mathrm{HgCl}_{2}-1 \%$ sodium acetate- $0.1 \%$ glutaraldehyde solution (buffered $\mathrm{HgCl}_{2}$-glutaraldehyde), $\mathrm{pH}$ 6.0. After fixation, tissues were stored overnight in $70 \%$ ethanol and, on the following day, were dehydrated through graded ethanols, cleared in xylene and embedded in paraffin.

The lectin, GSA II, was purchased from Sigma Chemical Company (St.Louis, Mo, USA) and conjugated to horseradish peroxidase (HRP, Type VI, Sigma)with glutaraldehyde according to a previously published procedure [4].

Sections from tissues fixed in buffered $\mathrm{HgCl}_{2}$-glutaraldehyde were treated with Lugol's solution prior to staining. The staining procedure using GSA II-HRP was similar to that described in an earlier report [5]. Briefly, tissue sections $5 \mu \mathrm{m}$ in thickness were flooded with a $10-20 \mu \mathrm{g} / \mathrm{ml}$ solution of lectin-HRP conjugate in $0.1 \mathrm{~mol} / 1$ phosphate-buffered saline (PBS), $\mathrm{pH} 7.2$, containing $0.1 \mathrm{mmol} / 1 \mathrm{CaCl}_{2}, \mathrm{MgCl}_{2}$ and $\mathrm{MnCl}_{2}$. After exposure to the lectinHRP conjugate for $2 \mathrm{~h}$ at $4{ }^{\circ} \mathrm{C}$, the tissue sections were rinsed with PBS and incubated in $0.03 \% 3,3^{\prime}$-diaminobenzidine- $0.006 \%$ hydrogen peroxide substrate medium ( $\mathrm{pH} 7.2-7.4)$ for $15 \mathrm{~min}$ at room temperature. Sections were then washed in PBS, followed by several quick rinses in distilled water, dehydrated through graded alcohols, cleared in xylene and cover slipped.

Attributing GSA II reactivity in certain sites to glycogen is contingent upon the ability of $\alpha$-glucosidases such as malt diastase and $\alpha$-amylase to eliminate this reactivity. Diastase and amylase are traditionally employed in histochemistry to digest glycogen specifically in tissue sections [6]. Accordingly, tissue sections adjacent to those exposed to GSA II-HRP were pretreated with one of the following enzyme solutions and then stained with lectin: (1) $0.1 \%$ purified malt diastase (Fischer Scientific, Springfield, NJ, USA), in buffered neutral saline $\left(0.8 \% \mathrm{NaCl}, 0.08 \% \mathrm{NaH}_{2} \mathrm{PO}_{4} \mathrm{H}_{2} \mathrm{O}, 0.12 \% \mathrm{Na}_{2} \mathrm{HPO}_{4}\right)$, for $20 \mathrm{~min}$ at $37^{\circ} \mathrm{C}$. (2) $1 \mathrm{mg} / \mathrm{ml} \alpha$-amylase (Sigma) in buffered neutral saline for $1 \mathrm{~h}$ at $37^{\circ} \mathrm{C}$.

Stained kidney sections of untreated diabetic rats at 14 days revealed GSA II reacting intensely with the cytoplasm of cells lining distal nephrons. Since this GSA II staining was eliminated by prior digestion with diastase and $\alpha$-amylase, thus providing evidence for glycogen in these tubules, we characterised the course of this glycogen deposition in a second phase of the study.

The second phase of the study employed 15 rats in which streptozotocin diabetes was induced and confirmed as described above. Three rats each were killed on days 1, 3, 6,9 and 12 following streptozotocin injection. After animals were anaesthetized with inactin $(100 \mathrm{mg} / \mathrm{kg})$, kidneys were excised and prepared for light microscopic evaluation according to the above procedures. Adjacent kidney sections were again stained with GSA II-HRP and PAS, with and without prior digestion with purified diastase or $\alpha$-amylase.

In a third phase of the study ultrastructural localisation of glycogen in kidneys was carried out after 14 days of diabetes. Four additional streptozotocin-diabetic rats, two of which were treated with insulin (1.75 $\mathrm{U}$ protamine zinc insulin daily) were studied. Plasma glucose levels were measured on day 13 after streptozotocin. The following day, animals were anaesthetized with inactin, their kidneys removed, sliced into small pieces, placed in $2.5 \%$ glutaraldehyde in $0.1 \mathrm{~mol} / 1$ PBS (pH 7.2-7.4), minced further into $1 \mathrm{~mm}^{3}$ pieces, and subsequently fixed for $2 \mathrm{~h}$ at $4{ }^{\circ} \mathrm{C}$. Following glutaraldehyde fixation, the tissue was post-fixed in $1 \% \mathrm{OsO}_{4}$ in $\mathrm{PBS}$ for $1 \mathrm{~h}$ at $4^{\circ} \mathrm{C}$, rinsed in PBS and stored in the buffer overnight at $4{ }^{\circ} \mathrm{C}$. On the following day, tissues were dehydrated and embedded in Epon 812. Ultrathin sections mounted on stainless steel grids were stained directly with the periodic acid - thiocarbohydrazide - silver proteinate (PA-TCH-SP) technique of Theiry [7].

Antiserum against human Tamm-Horsfall glycoprotein (Cappel Laboratories, Malvern, Penn, USA) was used as a marker for ascending thick limbs [8,9]. Immunolocalisation was performed on $5 \mu \mathrm{m}$ deparaffinised sections serial to those stained with GSA II-
HRP and PAS by using the avidin-biotin-peroxidase complex technique [10].

\section{Cytochemical controls}

Controls for lectin staining included (a) substitution of unconjugated GSA II for the lectin-HRP conjugate, (b) exposure of tissue sections to HRP and substrate medium without the lectin, (c) incubation of control sections with aqueous $2 \%$ periodic acid for $15 \mathrm{~min}$ prior to application of the lectin-HRP conjugate, (d) exposure to GSA II-HRP conjugate in presence of a $0.1 \mathrm{~mol} / 1$ concentration of each of the following sugars (Sigma): D-galactose, D-glucose, D-mannose, L-fucose, $\mathrm{N}$-acetyl-D-galactosamine, $\mathrm{N}$-acetyl-D-glucosamine, D-xylose, D-arabinose, sialic acid, and rabbit liver glycogen (Type III). Controls for the diastase and amylase pretreatments included incubation of tissue sections with neutral buffered saline without enzyme prior to GSA II-HRP and PAS staining. Controls for immunostaining required replacement of both goat antihuman Tamm-Horsfall glycoprotein with nonimmune serum from goat. Removal of the periodic acid step from the PA-TCH-SP sequence served as controls for the electron microscopic studies.

\section{Statistical analysis}

Comparison of plasma glucose levels was performed by Student's $\mathrm{t}$-test, and data are expressed as the mean $\pm \mathrm{SD}$.

\section{Results}

The average of plasma glucose levels in day 14 streptozotocin-diabetic rats not given insulin was $33.20 \pm$ $2.92 \mathrm{mmol} / 1$, compared to $6.96 \pm 0.44 \mathrm{mmol} / 1$ in control rats $(p<0.001)$. Diabetic rats treated with insulin showed plasma glucose levels of $12.04 \pm 2.87 \mathrm{mmol} / 1$, which were significantly reduced compared to untreated diabetic rats $(p<0.001)$, but still greater than levels in control animals $(p<0.001)$.

With light microscopy, alterations in renal morphology were not noticed until 14 days after administration of streptozotocin, and were restricted to animals not treated with insulin. Tissue sections from these kidneys stained with haemotoxylin and eosin showed marked swelling and vacuolization of the cells lining cortical but not medullary ascending thick limbs. Moderate dilatation, primarily of the cortical collecting system, was also seen in these specimens.

Table 1 summarises GSA II and PAS staining of kidneys from control and day 14 streptozotocin-diabetic rats. Sites stained with enzyme-resistant GSA II and PAS corresponded to the localisation of $\mathrm{N}$-acetylglucosamine-containing glycoconjugate and neutral glycoprotein, respectively. As shown in the first two sets of columns in the table, kidneys from untreated diabetic and control rats were equivalent in their distribution of glycoconjugate with terminal $\mathrm{N}$-acetylglucosamine or PAS-reactive glycoprotein (Table 1). However, the untreated diabetic rat kidneys differed from the control rat kidneys by showing lectin and PAS reactivity in their ascending thick limbs of the cortex and adjacent outer stripe of the outer medulla (third set of columns in Table 1). This staining was amylase- and diastase-la- 
Table 1. Griffonia simplicifolia agglutinin II (GSA II) and periodic acid-Schiff (PAS) staining of kidneys from control and untreated day 14 streptozotocin-diabetic rats

\begin{tabular}{|c|c|c|c|c|c|c|}
\hline \multirow[t]{3}{*}{$\begin{array}{l}\text { Uriniferous } \\
\text { component }\end{array}$} & \multicolumn{2}{|c|}{$\begin{array}{l}\text { Amylase- } \\
\text { and } \\
\text { diastase- } \\
\text { resistant } \\
\text { GSA II }\end{array}$} & \multicolumn{2}{|c|}{$\begin{array}{l}\text { Amylase- } \\
\text { and } \\
\text { diastase- } \\
\text { resistant } \\
\text { PAS }\end{array}$} & \multirow{2}{*}{\multicolumn{2}{|c|}{$\begin{array}{l}\text { Amylase- } \\
\text { and } \\
\text { diastase- } \\
\text { labile } \\
\text { GSA II, } \\
\text { PAS }\end{array}$}} \\
\hline & \multirow{2}{*}{$\begin{array}{l}\text { Con- } \\
\text { trol }\end{array}$} & \multirow{2}{*}{$\begin{array}{l}\text { Dia- } \\
\text { betic }\end{array}$} & \multirow{2}{*}{$\begin{array}{l}\text { Con- } \\
\text { trol }\end{array}$} & \multirow{2}{*}{$\begin{array}{l}\text { Dia- } \\
\text { betic }\end{array}$} & & \\
\hline & & & & & $\begin{array}{l}\text { Con- } \\
\text { trol }\end{array}$ & $\begin{array}{l}\text { Dia- } \\
\text { betic }\end{array}$ \\
\hline \multicolumn{7}{|l|}{ Glomerulus: } \\
\hline - podocyte & 0 & 0 & 0 & 0 & 0 & 0 \\
\hline - mesangial area & 0 & 0 & + & + & 0 & 0 \\
\hline $\begin{array}{l}\text { - vicinity of the } \\
\text { basement membrane }\end{array}$ & 0 & 0 & + & + & 0 & 0 \\
\hline \multicolumn{7}{|l|}{ Tubule epithelium: } \\
\hline - pars convoluta & 0 & 0 & + & + & 0 & 0 \\
\hline - pars recta & + & + & + & + & 0 & 0 \\
\hline Thin limbs & + & + & 0 & 0 & 0 & 0 \\
\hline \multicolumn{7}{|l|}{ Ascending thick limb } \\
\hline - medullary & 0 & 0 & 0 & 0 & 0 & $0-+$ \\
\hline - cortical & 0 & 0 & 0 & 0 & 0 & + \\
\hline \multicolumn{7}{|l|}{ Distal convoluted } \\
\hline \multicolumn{7}{|l|}{ Collecting düct } \\
\hline - initial (connecting) & $0-+$ & $0-+$ & 0 & 0 & 0 & 0 \\
\hline - medullary ray & $0_{-}+$ & $0-+$ & 0 & 0 & 0 & 0 \\
\hline - medullary & + & + & 0 & 0 & 0 & 0 \\
\hline \multirow{2}{*}{$\begin{array}{l}\text { Tubule basement } \\
\text { membrane }\end{array}$} & & & & & & 0 \\
\hline & 0 & 0 & + & + & 0 & 0 \\
\hline
\end{tabular}

Staining results are based on a subjectively estimated scale ranging from 0 to + , with 0 being unreactive and + being reactive. $0-+$ indicate that some cells, but not others, stained in a given tubule segment. Amylase- and diastase-labile GSA II and PAS staining for glycogen in ascending thick limbs occurred only in the untreated diabetic rat kidneys. Control and insulin-treated diabetic rat kidneys showed no staining in this site with GSA II and PAS

bile and thereby demonstrated glycogen. Kidneys from day 14 insulin-treated diabetic rats exhibited a lectin staining profile identical to that of the control group in all regions of the kidney.

To further examine the glycogen deposition in the ascending thick limbs of diabetic rat kidneys, a subsequent study was carried out. Three diabetic rats each were killed on days $1,3,6,9$ and 12 following streptozotocin injection. None of these diabetic rats received insulin and their average plasma glucose level following streptozotocin was $17.90 \pm 4.42 \mathrm{mmol} / 1$.

In two of these diabetic rats, glycogen was detected in renal tubules as early as 1 day after induction of diabetes (Fig.1). By 3 days, all diabetic rats showed diastase- and amylase-labile GSA II staining localising glycogen in the cytoplasm of most cells in the cortical but not medullary ascending thick limbs (Fig. 2A). Beyond three days, the number of lectin-reactive cells increased, so that by day 12 , GSA II stained nearly all of cells lining ascending thick limbs in the cortex of diabetic rats as well as in the adjacent medullary outer stripe (Fig. 3A). Glycogen accumulation in medullary

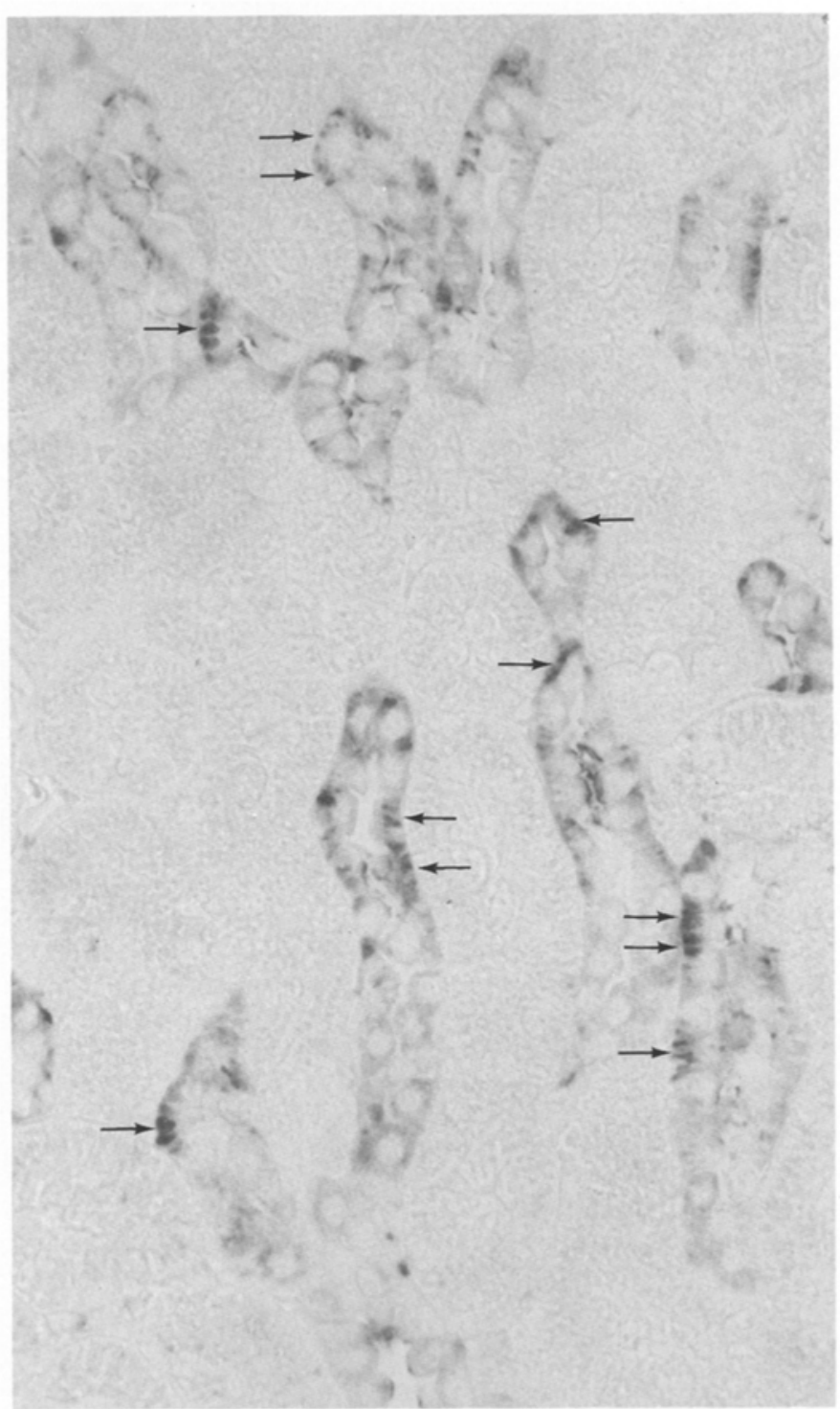

Fig. 1. Amylase- and diastase-labile Griffonia simplicifolia agglutinin II (GSA II) staining of glycogen in cortical ascending thick limbs $24 \mathrm{~h}$ after injection of streptozotocin. Lectin reactivity is localised primarily to the basal striations (arrows). In serial sections, the tubules shown above stained with anti-Tamm-Horsfall antiserum (not shown), which identified them as segments of the distal tubule. Magnification $\times 400$

outer stripe was not seen until day 12 and was never seen in the inner stripe of the outer medulla.

The GSA II lectin was more effective at demonstrating glycogen in tubules than the PAS reaction. Unlike the lectin, PAS could not detect glycogen in ascending thick limbs $24 \mathrm{~h}$ after injection of streptozotocin. On the third day of diabetes, PAS reacted with this site, but stained fewer glycogen-containing cells than did GSA II (Fig. 2B). In addition, the brown colouration imparted by GSA II had a distinct advantage over the lighter magenta shades of PAS in that cells stained lightly with PAS were highly visible when stained with the lectin (Fig. 2B). Not until 14 days after injection of streptozotocin did PAS clearly localise glycogen in any kidney region (Fig. 3 B). 


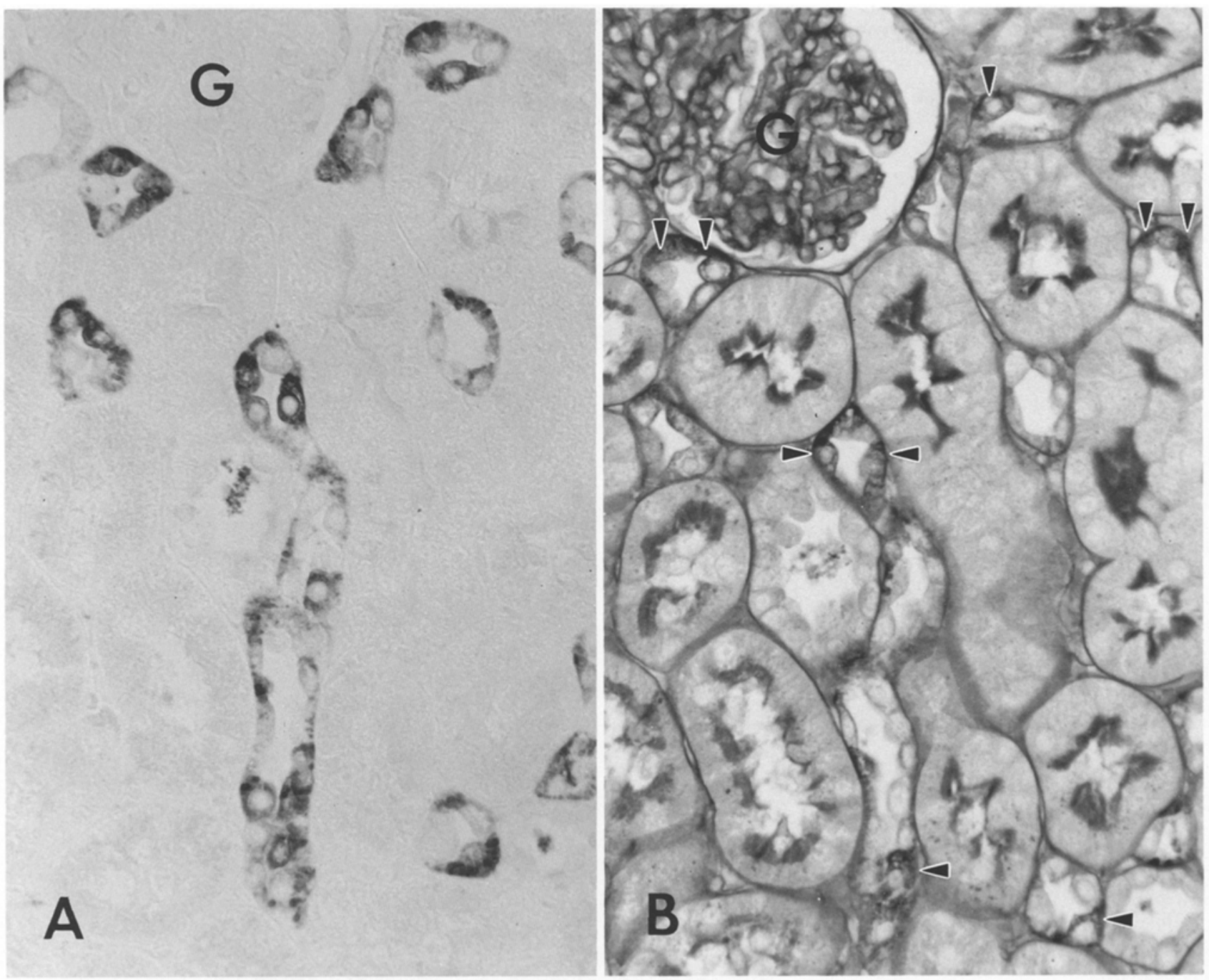

Fig. $2 \mathrm{~A}$ and B. Serial sections comparing amylase- and diastase-labile GSA II and PAS staining of glycogen in cortical ascending thick limbs 3 days after injection of streptozotocin. $\mathrm{G}=$ glomerulus. A GSA II staining is prominent and localises glycogen in numerous cells. B PAS staining of glycogen (arrows) first becomes apparent 3 days after onset of diabetes. Arrows point to cells containing PAS-reactive glycogen. However, fewer cells lining the ascending thick limbs appear stained when compared with GSA II. PAS reactivity in structures such as basement membranes and brush borders obscures much of the glycogen staining. Magnification $\times 400$

Ultrastructural assessment of the distal nephron glycogen deposition was performed in four diabetic rats 14 days after streptozotocin treatment. Two of these diabetic animals were not treated with insulin, so that their average plasma glucose levels were $(20.77 \pm$ $0.66 \mathrm{mmol} / 1$ at the time of killing. In the untreated diabetic rats, the PA-TCH-SP technique showed large accumulations of glycogen $\beta$-particles disrupting the cytoplasm of swollen cells lining the ascending thick limbs (Fig. 4A). Occasional mitochondria surrounded small pockets of $\beta$-particles enclosed by double-walled membranes (Fig. 4B). Two or three of these unusual mitochondrial profiles were seen in each swollen cell. Other morphological changes included blunted basal infoldings and a paucity of cell organelles (Fig. 4A). In addition, these cells contained several glycogenosomes, or glycogen-laden lysosomes (Fig.4C). No glycogen deposition and none of these structural changes were found in kidneys from the two diabetic rats treated with insulin.

\section{Control staining}

Control sections exposed to unconjugated lectin in place of GSA II-HRP conjugates or to HRP substrate medium without the lectin lacked any of the lectin specific staining described above. Treatment of control sections for $15 \mathrm{~min}$ with $2.0 \%$ periodic acid abolished all GSA II staining. In experiments where GSA IIHRP conjugates at 10-20 $\mu \mathrm{g} / \mathrm{ml}$ were preincubated for $24 \mathrm{~h}$ at $4{ }^{\circ} \mathrm{C}$ with $0.1 \mathrm{~mol} / 1$ concentration of nine different monosaccharides and glycogen, $\mathrm{N}$-acetylglucosamine, glucose and rabbit liver glycogen abolished staining. The other sugars failed to inhibit staining. Prior incubation of tissue sections with neutral buffered saline without diastase or amylase failed to affect 

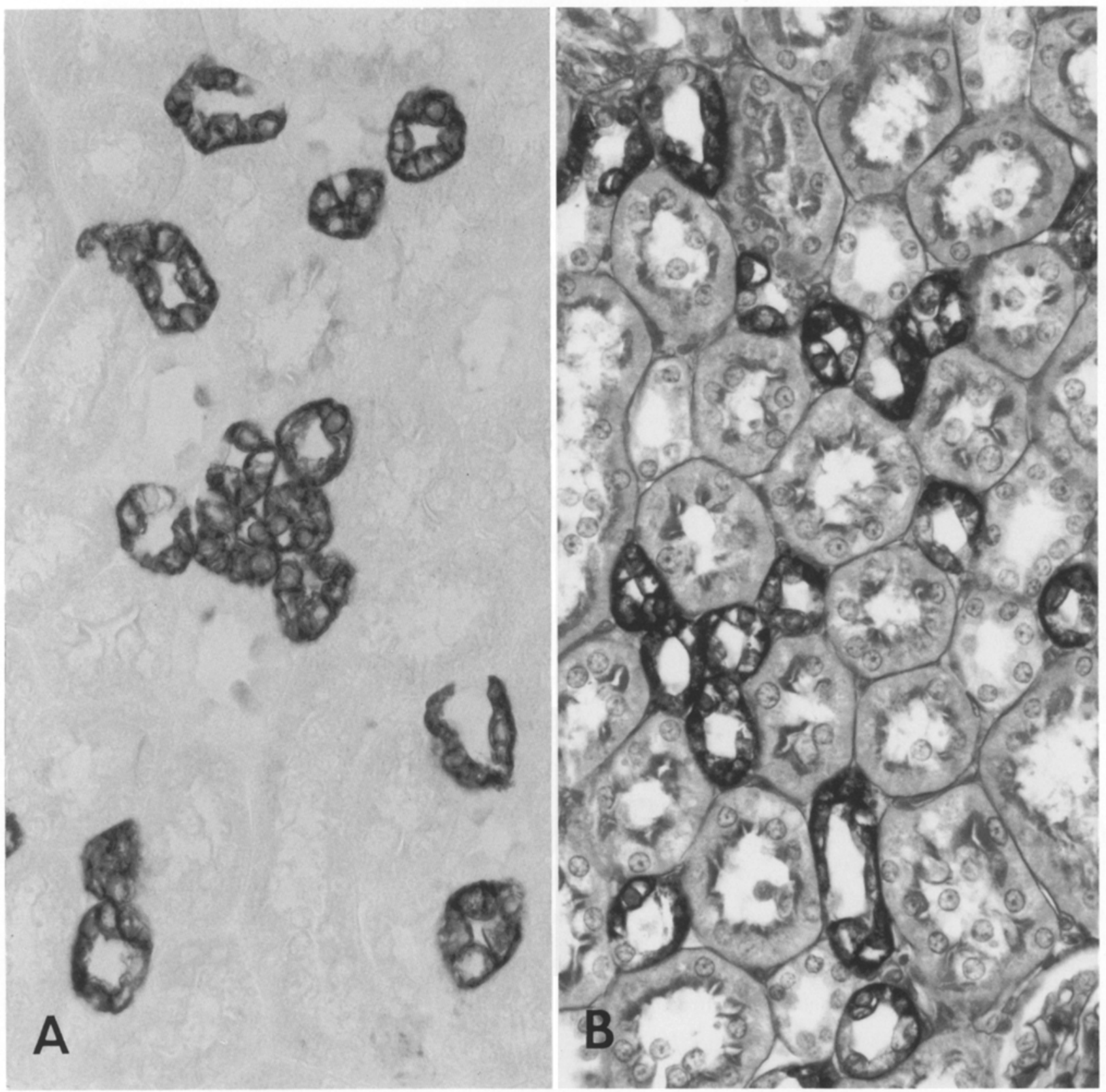

Fig.3A and B. Comparison of GSA II and PAS staining of glycogen in kidney cortex 14 days after injection of streptozotocin. Virtually all of the cells lining the ascending thick limbs show intense cytoplasmic staining with GSA II (A) and PAS (B). These are adjacent but not serial sections. Magnification $\times 400$

GSA II and PAS staining of glycogen. In the PA-TCHSP procedure, deletion of periodic acid (PA) necessary for oxidation of glucose residues in glycogen, failed to produce the specific staining of glycogen seen with the PA-TCH-SP procedure applied to diabetic rat kidneys.

Immunostaining for Tamm-Horsfall glycoprotein imparted colouration to cells lining ascending thick limbs as previously described $[5,6]$. Adjacent sections to those treated with anti-Tamm-Horsfall glycoprotein were incubated with nonimmune serum from goat. No specific staining was identified in any of these sections for the histologic sites containing Tamm-Horsfall glycoprotein.

\section{Discussion}

Our study describes the use of GSA II in the histochemical examination of glycogen in animals with experimental diabetes mellitus. GSA II demonstrates excess glycogen in the ascending thick limb of diabetic rat kidneys. This finding is consistent with earlier reports using PAS to localise complex carbohydrate [2, $11,12]$. In these previous studies, the earliest detection of glycogen deposition was 14 days after induction of diabetes [11]. However, using the GSA II-HRP conjugate, we localised the glucose homopolysaccharide in distal tubules within $24 \mathrm{~h}$ after streptozotocin treat- 

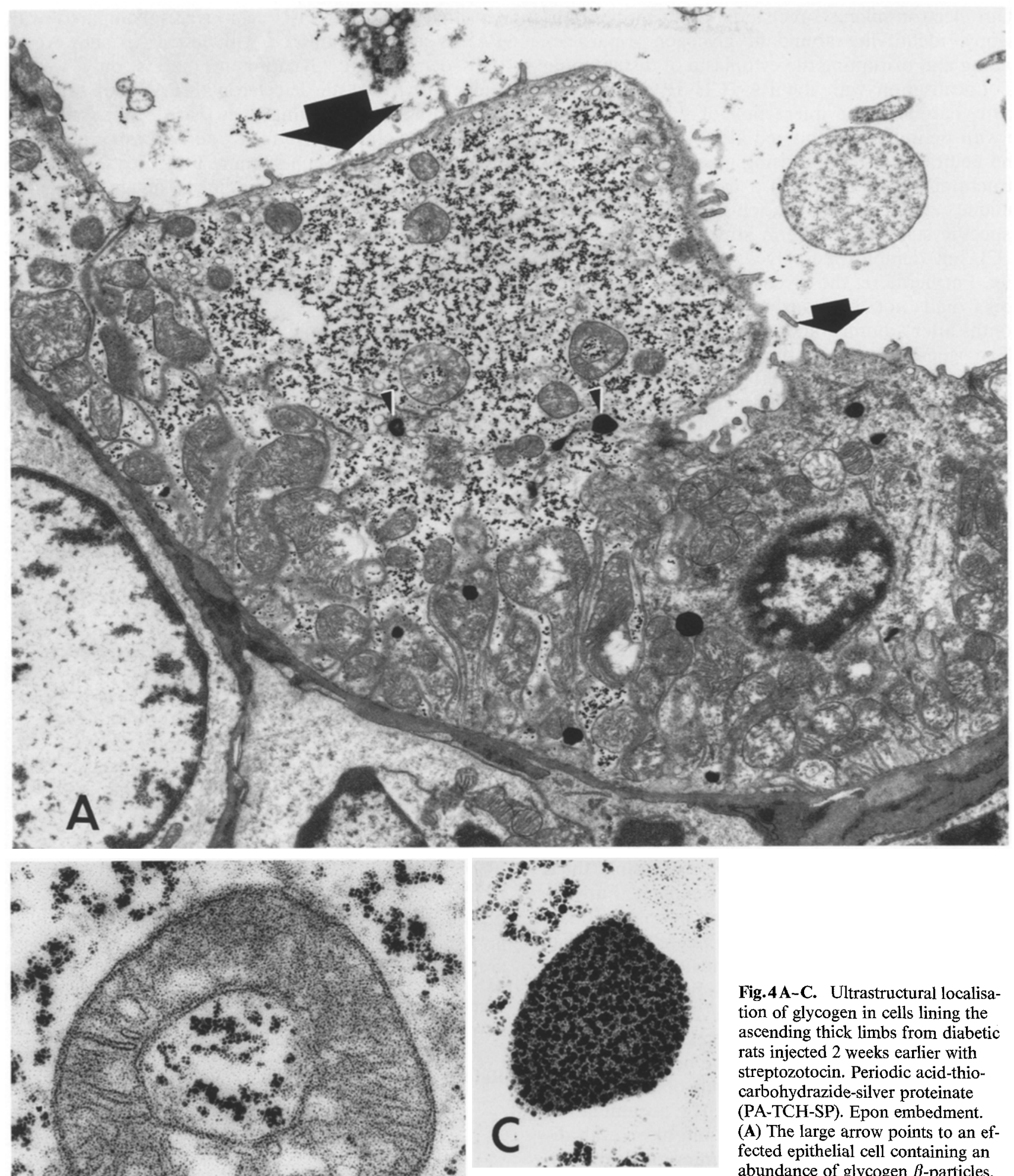

Fig.4 A-C. Ultrastructural localisation of glycogen in cells lining the ascending thick limbs from diabetic rats injected 2 weeks earlier with streptozotocin. Periodic acid-thiocarbohydrazide-silver proteinate (PA-TCH-SP). Epon embedment. (A) The large arrow points to an effected epithelial cell containing an abundance of glycogen $\beta$-particles. An adjacent cell (smaller arrow) displays a relatively normal morphology. Small arrowheads point to scattered glycogenosomes, one of which is magnified in Figure 4C. Original magnification $\times 3000$. (B) Mitochondrion surrounding a focus of glycogen. These profiles were common in the glycogen-laden cells. Original magnification $\times 20000$. (C) Glycogenosomes. Original magnification $\times 20000$

ment. At this early time, glycogen is found only in cortical ascending thick limbs, but by 12 days glycogen deposition occurs in ascending thick limbs in the outer, but not inner, stripe of the outer medulla. The differ- ence in the properties of the cortex and medulla which result in glycogen deposition occurring primarily in one kidney region and only partially in the other is unknown. 
Our electron microscopic studies confirm light microscopy, identifying abundant glycogen $\beta$-particles crowding and disrupting the cytoplasm of distal tubule cells. Localisation with the PA-TCH-SP sequence is specific, based on the interaction of thiocarbohydrazide with periodate-engendered aldehydes of 1,2-diols in the neutral sugars comprising glycogen [7]. Our ultrastructural localisation with a carbohydrate-specific technique also confirms Rasch's findings using a nonspecific stain in long-term streptozotocin-diabetic rats [2], but demonstrates glycogen deposition much earlier. Furthermore, the glycogenosomes seen here at 2 weeks had not previously been identified until 4 months after administration of streptozotocin [13].

Glycogen deposition in the distal tubules of diabetic rats may be related to the effects of diabetes on the enzymes which synthesize and degrade glycogen, processes that occur to a greater extent in the distal than proximal tubule. Khandelwal et al. [14] found that total renal glycogen synthase activity was elevated in diabetic rats. However, the significance of this increase in total activity is unclear since the insulin-sensitive fraction was reduced. Other biochemical studies showed an increase in the activity of renal hexokinase [15-17], an enzyme that occurs primarily along the distal tubule $[18,19]$. Together these findings suggest that accelerated synthesis may be partially responsible for glycogen accumulation. On the other hand, impairment of glycogenolytic enzymes, specifically lysosomal $\alpha 1,4$-glucosidase, was suggested by Orci and Stauffacher [13] to explain excess glycogen in lysosomes and possibly in the cytoplasm of cells lining tubules in diabetic rat kidneys.

Whatever the mechanisms, histochemical procedures employed in the present study localise the altered glycogen metabolism to the ascending thick limbs and primarily to the cortical segment. Furthermore, this abnormality was prevented by insulin treatment, evidence that the changes are related to the diabetic state rather than streptozotocin itself. Glycogen accumulation was prevented by insulin treatment despite moderately but persistently elevated plasma glucose levels. However, overall glycaemic control in the insulin-treated diabetic rats may have been better than indicated by the plasma glucose levels obtained at the end of the first phase of the study. The accumulation of glycogen in the thick ascending limb may result directly from changes in glycogen forming or degrading enzymes due directly to insulin deficiency rather than systemic hyperglycaemia. If so, insulin replacement through the peripheral circulation that was inadequate to normalise glycosuria may have adequately insulinised the kidney. Whatever the case, renal glycogen accumulation could be prevented by modest insulin treatment.

The ability of GSA II-HRP to detect glycogen accumulation earlier than PAS substantiates claims that the lectin is more sensitive for glycogen [1]. Greater sensitivity of lectin-HRP conjugates compared with PAS is also encountered with lectins in sites where they demonstrate glycoprotein that is only weakly stained or not at all detected with PAS. For example, cells lining the collecting duct that do not stain with PAS show intense luminal surface staining with GSA II (Table 1). Such staining amplification may be attributed in part to lectin binding to sugars lacking the PAS-reactive 1,2-diols but probably also reflects more sensitive demonstration of glycoconjugate containing periodate-reactive sugars. Conceivably, this property of GSA II could have widespread utilisation in the study of glycogen metabolism in the numerous organs affected by diabetes mellitus.

The utility of lectins in the analysis of the streptozotocin-diabetes model is demonstrated further in other recent reports. Rosenquist and Huff [20] used GSA II and concanavalin A conjugated to ferritin to demonstrate increased lectin staining of glomerular and tubule basement membrane and renal brush border in rats with long-term ( $\geqq 70$ days) streptozotocin diabetes. In another report, Hawthorne et al. [21] applied wheat germ agglutinin to paraffin sections of kidney from streptozotocin-diabetic rats, and, after six months, showed a possible increase of glycoconjugate containing $\mathrm{N}$-acetylglucosamine within glomeruli. That we did not find changes in lectin staining in areas described by these studies may be related to the shorter duration of diabetes in rats. Although it is likely that numerous changes in constituent carbohydrates of the kidney occur in diabetes and that these changes may occur after different durations, our study suggests that lectin histochemistry may be a sensitive method for earliest detection.

Acknowledgements. The authors wish to thank Ms. LaBreck for her technical assistance. Also, the excellent editorial and typing skills of Ms. Nelson are greatly appreciated. Photographic expertise was provided by Mr. Nicholson. This research was funded by grants from the National Institutes of Health (AM32889 and DK35977). During this study, Dr. Harvey was a Research Postdoctorial Fellow supported by the College of Graduate Studies, Medical University of South Carolina.

\section{References}

1. Hennigar RA, Schulte BA, Spicer SS (1987) Histochemical detection of glycogen using Griffonia simplicifolia agglutinin II. Histochem J 18: 589-596

2. Rasch R (1984) Tubular lesions in streptozotocin-diabetic rats. Diabetologia 27: 32-37

3. Kadish AH, Little RL, Sternberg JC (1968) A new and rapid method for the determination of glucose by measurement of rate of oxygen consumption. Clin Chem 14: 116-131

4. Schulte BA, Spicer SS (1983) Light microscopic detection of sugar residues in glycoconjugates of salivary glands and the pancreas with lectin-horseradish peroxidase conjugates. I. Mouse. Histochem J 15: 1217-1238

5. Hennigar RA, Schulte BA, Spicer SS (1985) Heterogeneous distribution of glycoconjugates in human kidney tubules. Anat Rec 211: $376-390$ 
6. Lillie RD, Fullmer HM (1976) Histopathologic technique and practical histochemistry. McGraw Hill, London, pp 629-630

7. Thiery JP (1967) Mise en evidence der polysaccharides sur coupes fines en microscopie electronique. J Microsc 6: 987-1018

8. Schenk EA, Schwartz RH, Sewis RA (1971) Tamm-Horsfall mucoprotein. I. Localization in the kidney. Lab Invest 25: 92-95

9. Hoyer JR, Seiler MW (1979) Pathophysiology of Tamm-Horsfall protein. Kidney Int 16:279-289

10. Hsu SM, Raine L, Fanger J (1981) Use of avidin-biotin-peroxidase complex $(\mathrm{ABC})$ in immunoperoxidase techniques. A comparison between $\mathrm{ABC}$ and unlabelled antibody (PAP) procedures. J Histochem Cytochem 29: 577-580

11. Wehner H, Kosters W, Strauch M, Staudenmeir M (1980) Effect of islet transplantation on the glomerular changes in streptozotocin-diabetic rats. Virchows Arch [A] 388: 137-154

12. Bleasel AF, Yong LCJ (1982) Streptozotocin-induced diabetic nephropathy and renal tumors in the rat. Experientia 38: $129-130$

13. Orci L, Stauffacher W (1971) Glycogenosomes in renal tubular cells of diabetic animals. J Ultrastruct Res 36: 499-503

14. Khandelwal RL, Zinman SM, Knull HR (1979) The effect of streptozotocin-induced diabetes in glycogen metabolism in rat kidney and its relationship to the liver system. Arch Biochem Biophys 197: 310-316

15. Anderson JW, Stowring L (1973) Glycolytic and gluconeogenic enzyme activities in renal cortex of diabetic rats. Am J Physiol 224: 930-936

16. Lemieux G, Aranda MR, Fournel P, Lemieux C (1984) Renal enzymes during experimental diabetes mellitus in the rat. Role of insulin, carbohydrate metabolism, and ketoacidosis. Can J Physiol Pharmacol 62: 70-75

17. Sochor M, Baquer WZ, McLean P (1979) Glucose overutilization in diabetes: Evidence from studies on the changes in hexokinase, the pentose phosphate pathway and glucuronate-xylulose pathway in rat kidney cortex in diabetes. Biochem Biophys Res Commun 86: 32-39

18. Guder WG, Ross BD (1984) Enzyme distribution along the nephron. Kidney Int 26: 101-111

19. Lawrence GM, Trayer IP (1984) Histochemical and immunohistochemical localization of hexokinase isoenzymes in rat kidney. Histochem J 15: 697-708

20. Rosenquist TH, Huff $\mathrm{T}$ (1985) Lectin binding in the diabetic rat kidney. Histochemistry $83: 279-284$

21. Hawthorne GC, MacLellan JR, Mythen M, Alberti KGMM, Turner GA (1986) Studies on glomerular basement membrane in experimental diabetes using lectin histochemistry in Wistar rats. Diabetologia 29: 495-499

Received: 6May 1987

and in revised form: 10 August 1987

Dr. Randolph A. Hennigar

Department of Pathology

Medical University of South Carolina

171 Ashley Avenue

Charleston, SC 29425

USA 